\title{
Pengaruh Manajemen Laba Terhadap Nilai Perusahaan
}

\author{
Pedi Riswandi ${ }^{1}$, Rina Yuniarti ${ }^{*}$ \\ ${ }^{1}$ Fakultas Ekonomi, Universitas Prof. Dr. Hazairin, SH.,MH Bengkulu \\ ${ }^{2}$ Fakultas Ekonomi, Universitas Muhammadiyah Bengkulu \\ Email: rinayuniarti2013@gmail.com
}

Naskah diterima 21 Maret 2020, Revisi 30 Maret 2020, Terbit 19 April 2020

\begin{abstract}
Abstrak
DOI: doi.org/10.21107/pamator.v13i1.6953

Tujuan berdirinya suatu perusahaan untuk meningkatkan nilai perusahaan, sehingga dapat memberikan kemakmuran bagi pemegang saham. Salah satu faktor yang dapat memengaruhi nilai perusahaan adalah manajemen laba. Penelitian ini bertujuan untuk menguji secara empiris pengaruh manajemen laba terhadap nilai perusahaan. Sampel penelitian ini perusahaan pertambangan sebanyak 154 terdaftar di Bursa Efek Indonesia tahun 2012-2017. Data yang digunakan adalah data sekunder yang diperoleh dari laporan keuangan dan laporan tahunan perusahaan. Hasil penelitian menunjukkan bahwa manajemen laba berpengaruh positif signifikan terhadap nilai perusahaan
\end{abstract}

Kata Kunci : manajemen laba, nilai perusahaan, bursa efek Indonesia

\begin{abstract}
The purpose of the establishment of a company is to increase the firm value can give prosperity for shareholders. A factor can affect firm values is earning management. This research aims to empirically examine the effects of earnings management on firm value. The sample is 154 mining companies listed on the Indonesian Stock Exchange in 2012-2017. The type of data used is secondary data obtained from the company's financial statement and annual reports. The result showed that earnings management has a positive effect on firm value..
\end{abstract}

Keywords : earnings management, corporate value, Indonesia stock exchange

\section{PENDAHULUAN}

Perusahaan-perusahaan saat ini saling bersaing agar menjadi perusahaan yang berkompeten diantara perusahaan lain. Sari \& Priyadi (2016), mengungkapkan nilai perusahaan bagian dari persepsi investor terhadap perusahaan terkait harga saham, semakin tinggi nilai perusahaan dapat memberikan kemakmuran bagi pemegang saham (Nurhayati, 2013). Merosotnya harga saham PT Bumi Resources Tbk (BUMI) terjadi awal September 2017 berada di level terendah 212 dan tertinggi 258 per saham, sehingga masuk jajaran daftar top losers atau saham turun paling dalam.

Subanidja et al, (2016), mengungkapkan manajemen laba adalah upaya manajemen yang disengaja untuk memanipulasi laporan keuangan dalam batas yang diizinkan oleh prinsip akuntansi. Praktik manajemen laba dapat menyebabkan pengungkapan informasi dalam laporan keuanga tidak mencerminkan kondisi sebenarnya (Herman \& Purwanto, 2014). PT Timah Tbk dituding telah melakukan manipulasi laporan keuangan terlihat dari laporan keuangan semester I-2015 menunjukkan kinerja yang positif padahal laba operasi rugi sebesar Rp. 59 miliar (Afriyanto, 2019).

Yorke et al., (2016), hasil penelitian menunjukkan bahwa manajemen laba menurunkan nilai perusahaan. Jong et al (2014), tindakan manajemen laba yang dilakukan manajer dapat menghancurkan nilai perusahaan untuk jangka panjang. Gill et al., (2013), perusahaan yang melakukan manajemen laba akan menurunkan harga saham dan nilai pasar perusahaan. Manajemen sering melakukan manajemen laba dalam lingkup kebijakan hukum dan akuntansi (Li et al., 2017). Tandry et al., (2014), mengungkapkan bahwa manajemen akan membuat laporan keuangan sebaik mungkin untuk menarik 
investor agar berinvestasi di perusahaan. Sementara Suffian et al., (2015), mengungkapkan bahwa manajemen laba dapat meningkatkan nilai perusahaan. Helmayunita \& Sari (2013), manajemen laba yang dilakukan perusahaan dapat menaikkan nilai perusahaan dalam jangka waktu pendek.

Teori agensi mengungkapkan bahwa pemegang saham pengendali utama mengendalikan dan memantau para manajer dalam melakukan kegiatan bisns di perusahaan untuk meminimalisir masalah keagenan dapat mengurangi biaya agendi berdampak peningkatan nilai perusahaan (Kim et al., 2017). Penelitian ini menggunakan sektor pertambangan karena produksi minyak bumi dan batu bara dari tahun 2012-2015 mengalami penurunan, sedangkan minyak bumi dan batu bara merupakan komoditi dari sektor pertambangan. Ketika kedua komoditi mengalami penurunan berdampak pada harga saham. Harga saham rendah maka investor enggan berinvestasi pada perusahaan sehingga nilai perusahaan menurun.

Hasil penelitian yang belum konsisten dan fenomena yang ada memotivasi peneliti untuk menguji kembali pengaruh manajemen laba terhadap nilai perusahaan. Tujuan penelitian ini untuk menguji pengaruh manajemen laba terhadap nilai perusahaan.

\section{METODOLOGI}

Penelitian yang digunakan pada penelitian ini adalah penellitian kuantitatif. Nilai perusahaan sebagai nilai pasar perusaaa dibagi dengan penggantian modal. Pengukuran nilai perusahaan menggunakan Tobin's $Q$ yang digunakan oleh (Chung \& Pruitt, 2007).

$$
\text { Tobin's } Q=\frac{M V E+D e b t}{T A}
$$

Keterangan:

$$
\begin{array}{ll}
\text { Tobin's } \mathrm{Q}= & \text { Nilai Perusahaan } \\
\text { MVE } & \text { Market value of equity (closing } \\
& \begin{array}{l}
\text { price } \mathrm{x} \text { jumlah saham } \\
\text { beredar) }
\end{array} \\
\text { Debt }= & \begin{array}{l}
\text { Total hutang (kewajiban } \\
\text { lancar-aset lancar+hutang } \\
\text { jangka panjang). }
\end{array} \\
\text { TA } & =\begin{array}{l}
\text { nilai buku dari total aset }
\end{array}
\end{array}
$$

Praktik manajemen laba dinilai merugikan pihak investor karena praktik manajemen laba dapat menurunkan kualitas laporan keuangan dan memberikan informasi yang tidak relevan (Darwis, 2012). Proksi manajemen laba dalam penelitian ini adalah Discretionnary Accruals menggunakan Modified Jones Model. Langkah-langkah untuk menghitung rumus Discretionary Accrual Modified Jones Model sebagai berikut :

1. Mengukur total accrual

$$
\mathrm{TA}_{\mathrm{i}, \mathrm{t}}=N \mathrm{I}_{i, t}-C F O_{i, t}
$$

Keterangan :

Tait : Total acrual perusahaan i pada periode waktu ke $t$

Niit : Laba bersih perusahaan i pada periode waktu ke t

CFOit : Arus kas operasi perusahaan i pada periode waktu ke $t$

2. Menghitung nilai total accrual yang diestimasi dengan persamaan regresi OLS

$$
\begin{gathered}
\frac{T A_{i t}}{A_{i t-1}}=\beta_{1}\left(\frac{1}{A_{i t-1}}\right)+\beta_{2}\left(\frac{\Delta \operatorname{Rev}_{t}}{A_{i t-1}}-\frac{\Delta \operatorname{Rec}_{t}}{A_{i t-1}}\right)+ \\
\quad \beta_{3}\left(\frac{P P E_{t}}{A_{i t-1}}\right) \ldots \ldots \ldots \ldots \ldots \ldots \ldots \ldots \ldots \ldots \ldots \ldots \ldots \ldots
\end{gathered}
$$

Keterangan :

$\mathrm{A}_{\mathrm{it}-1} \quad$ : Total aset perusahaan i pada periode ke t-1

$\Delta \operatorname{Rev}_{\mathrm{t}}$ : Perubahan pendapatan perusahaan i pada periode ke $\mathrm{t}$

$\Delta \operatorname{Rec}_{t} \quad$ : Perubahan piutang perusahaan i pada periode ke $t$

$\mathrm{PPE}_{\mathrm{t}}=$ Aset tetap perusahaan i pada periode ke $t$

3. Kemudian dari persamaan yang kedua diregresi dan muncul nilai residual. Standard Residual Value tersebut akan diabsolutkan.

4. Hasil Standardized Residual yang telah diabsolutkan digunakan untuk menguji hipotesis

Populasi yang digunakan dalam penelitian ini adalah perusahaan pertambangan yang terdaftar di Bursa Efek Indonesia (BEI) periode 2012-2017. Teknik pengambilan sampel adalah sampel jenuh. Sampel jenuh adalah teknik penentuan sampel bila semua anggota populasi digunakan sebagai sampel. Berikut ini merupakan sampel penelitian yang digunakan dalam penelitian ini : 
Tabel 1. Penentuan Sampel Perusahaan

Pertambangan

\begin{tabular}{llcccccc}
$\mathrm{N}$ & $\begin{array}{c}\text { Keteranga } \\
\mathrm{n}\end{array}$ & 201 & 201 & 201 & 201 & 201 & 201 \\
& 2 & 3 & 4 & 5 & 6 & 7 \\
\hline 1 & $\begin{array}{l}\text { Terdaftar } \\
\text { di BEI }\end{array}$ & 37 & 37 & 38 & 39 & 39 & 41 \\
\hline 2. & $\begin{array}{l}\text { Perusaha } \\
\text { an yang } \\
\text { mengalam } \\
\text { i kerugian }\end{array}$ & 9 & 11 & 12 & 21 & 15 & 9 \\
\hline & & & & & & \\
\hline & Total & 28 & 26 & 26 & 18 & 24 & 32 \\
\hline
\end{tabular}

Teknik analisis data yang digunakan dalam penelitian ini adalah regresi linier. Sebelum dilakukan pengujian hipotesis maka dilakukan analisis statistik deskriptif dan uji multikolonieritas

\section{HASIL PEMBAHASAN}

Analisis Statistik Deskriptif

Analisis statistik deskriptif bertujuan untuk mengetahui nilai rata-rata (mean), maksimum, minimum dan standar deviasi dari masing-masing variabel. Statistik deskriptif disajikan pada Tabel 2 berikut : Tabel 2. Analisis Statitistik Deskriptif

\begin{tabular}{|c|c|c|c|c|c|}
\hline Variabel & $\mathrm{N}$ & Min & Maks & Mean & $\begin{array}{c}\text { Std. } \\
\text { Deviasi }\end{array}$ \\
\hline $\begin{array}{c}\text { Tobin's } \\
\mathrm{Q}\end{array}$ & 154 & 0.02 & 8.44 & 1.16 & 1.26 \\
\hline $\begin{array}{c}\text { Manaje } \\
\text { men } \\
\text { Laba }\end{array}$ & 154 & 0.00 & 4.76 & 0.68 & 0.72 \\
\hline
\end{tabular}

Berdasarkan Tabel 2 menunjukkan nilai rata-rata Tobin's $Q$ diproksikan sebagai variabel nilai perusahaan sebesar 1.16. nilai maksimum sebesar 8.44 yang dimiliki oleh PT Golden Eagle Energy Tbk (SMMT) pada tahun 2013. Nilai minimum sebesar 0.02 yang dimiliki oleh PT ATPK Resources Tbk (ATPK) pada tahun 2013. Nilai rata-rata variabel manajemen laba sebesar 0.68 . nilai maksimum sebesar 4.76 dimiliki oleh PT Garda Tujuh Buana Tbk (GTBO) pada tahun 2012. Nilai minimum sebesar 0.00 yang dimiliki oleh PT Vale Indonesia Tbk (INCO) pada tahun 2016.

\section{Uji Multikolinieritas}

Uji ini digunakan untuk mengetahui ada tidaknya hubungan linear antara variabel independen dalam model regresi. Hasil uji multikolinearitas dapat disajikan pada Tabel 3 berikut:
Tabel 3. Pengujian Multikolinearitas

\begin{tabular}{|c|c|c|c|}
\hline Variabel & Tolerance & VIF & Keterangan \\
\hline $\begin{array}{l}\text { Manajemen } \\
\text { Laba }\end{array}$ & 0.916 & 1.092 & $\begin{array}{c}\text { Bebas uji } \\
\text { multikolinearitas }\end{array}$ \\
\hline \multicolumn{4}{|c|}{ Analisis Regresi Linier Sederhana } \\
\hline $\begin{array}{l}\text { Analisis } \\
\text { dilakukan } \\
\text { manajeme } \\
\text { Hasil uji } \\
\text { berikut: }\end{array}$ & $\begin{array}{c}\text { regres } \\
\text { untuk } \\
\text { laba terk } \\
\text { egresi lin }\end{array}$ & $\begin{array}{l}\text { lin } \\
\text { men } \\
\text { ladap } r \\
\text { er sec }\end{array}$ & $\begin{array}{lr}\text { r } & \text { sederhana } \\
\text { uji } & \text { pengaruh } \\
\text { lai perusahaan. } \\
\text { erhana sebagai }\end{array}$ \\
\hline
\end{tabular}

Tabel 4. Pengujian Hipotesis

\begin{tabular}{llllll}
\hline & \multicolumn{2}{c}{$\begin{array}{c}\text { Unstandardized } \\
\text { Coefficient }\end{array}$} & $t$ & sig & Kesimpulan \\
& $\beta$ & $\begin{array}{l}\text { Std } \\
\text { Error }\end{array}$ & & & \\
\hline Constant & 1.574 & 2.149 & 0.73 & 0.465 & \\
$\begin{array}{l}\text { Manajemen } \\
\text { Laba }\end{array}$ & 0.475 & 0.138 & 3.44 & 0.001 & $\begin{array}{l}\text { Hipotesis } \\
\text { ditolak }\end{array}$ \\
\hline
\end{tabular}

Berdasarkan Tabel 4, menunjukkan nilai $\beta$ dari manajemen laba sebesar 0.475 dan bernilai positif. Hal ini menunjukkan semakin tinggi manajemen laba semakin tinggi nilai perusahaan. Nilai signifikansi dari manajemen laba terhadap nilai perusahaan sebesar 0.01 . sehingga manajemen laba berpengaruh positif signifikan terhadap nilai perusahaan.

Analisis statistik nilai signifikansi manajemen laba sebesar 0.01 dan nilai tersebut lebih kecil dari $\alpha=0.01$. Nilai $\beta$ sebesar 0.475 dan bernilai positif, maka disimpulkan bahwa manajemen laba berpengaruh positif dan signifikan terhadap nilai perusahaan.

Hasil penelitian ini sesuai dengan Foerster et al., (2009), mengungkapkan bahwa manajemen laba berpengaruh positif terhadap nilai perusahaan. Salah satu cara untuk meningkatkan nilai perusahaan adalah dengan melakukan manajemen laba. Praktik manajemen laba, perusahaan akan menyajikan laporan keuangan sebaik mungkin sehingga nilai perusahaan dapat meningkat. Akan tetapi praktik manajemen laba dapat meningkatkan nilai perusahaan dalam skala kecil (Tandry et al., 2014). Suprianto \& Setiawan (2018), manajer melakukan manajemen laba sebagai alat untuk menyampaikan sinyal positif kepada pemegang saham tentang kinerja masa depa melalui pendapatan perusahaan. 
Jong et al., (2014) menyatakan bahwa analis dan CFO percaya bahwa memenuhi standar pendapatan dan kenaikan laba dapat meningkatkan nilai perusahaan. Akan tetapi terdapat perbedaan tolak ukur tindakan manajemen laba antara CFO dan analis. Pandangan CFO untuk memenuhi tolak ukur yaitu mengurangi pengeluaran diskresioner dan menunda dimulainya proyek baru sedangkan pandangan analis bahwa hanya melakukan pembelian kembali saham dapat meningkatkan nilai perusahaan. Li et al., (2017), manajemen sering kali menggunakan manajemen laba untuk memaksimalkan kepentingannya dalam lingkup kebijakan legal dan akuntansi. Manajemem laba untuk jangka pendek kemungkinan akan meningkatkan nilai perusahaan akan tetapi menurunkan nilai perusaaan dalam jangka panjang.

Teori agensi yang digunakan peneliti belum mampu mendiskripsikan pengaruh negatif dalam pengujian manajemen laba terhadap nilai perusahaan. Penggunaan pengukuran modifikasi jones dalam mendeteksi manajemen laba dimungkinkan kurang sesuai dengan teori agensi yang telah digunakan peneliti.

\section{KESIMPULAN}

Berdasarkan hasil penelitian yang telah di bahas pada bab sebelumnya, maka diperoleh kesimpulan bahwa manajemen laba berpengaruh positif terhadap nilai perusahaan. Hasil penelitian ini memberikan beberapa implikasi untuk investor diharapkan mampu memberikan informasi kepada para pemegang saham terkait bagaimana kecenderugan manajer melakukan manajemen laba. Tindakan manajemen laba dilakukan para manajer keuangan untuk memenuhi kepentingan pribadi.

Keterbatasan penelitian ini, teori agensi yang digunakan peneliti belum mampu mendeskripsikan pengaruh negatif manajemen laba terhadap nilai perusahaan. Penggunaan pengukuran modifikasi jones dalam mendeteksi manajemen laba kemungkinan kurang sesuai dengan teori agensi yang telah digunakan peneliti. Saran untuk penelitian selanjutnya dapat menggunakan teori sinyal. Teori sinyal mampu memberikan bukti bahwa manajemen laba memiliki pengaruh positif terhadap nilai perusahaan.

\section{DAFTAR PUSTAKA}

Afriyanto, D. 2019. Direksi Timah Dituding Manipulasi Laporan Keuangan. http://economy.okezone.com/read/20 16/01/27/27/1298264/direksi-timahdituding-manipulasi-laporankeuangan.Diakses 1 November 2019

Chung, K. H., \& Pruitt, S. W. 2007. A Simple Approximation of Tobin's q. Financial Management. Vol 23. No 3. 70. https://doi.org/10.2307/3665623

Darwis, H. 2012. Manajemen Laba terhadap Nilai Perusahaan degan Corporate Governance sebagai Pemoderasi. Jurnal Keuangan dan Perbankan, Vol 16. No 1.

Foerster, S. R., Sapp, S. G., \& Shi, Y. 2009. The impact of management earnings forecast on firm resk and firm value. $A A A$ 2010. Financial Accouting and Reporting Sections (FARS).

Gill, A., Biger, N., Mand, H. S., \& Mathur, N. 2013. Earnings management, firm performance, and the value of Indian manufacturing firms. International Research Journal of Finance and Economics. Vol 116. 13-26 pp.

Helmayunita, N., \& Sari, V. F. 2013. Pengaruh Manajemen Laba dan Struktur Kepemilikkkan Perusahaan terhadap Nilai Perusahaan. Wahana Riset Akuntansi. Vol 1. No 1.

Herman, M. B., \& Purwanto, A. 2014. Pengaruh Manajemen Laba, Resiko Pasar, Komite Audit, Audit Eksternal dan Struktur Kepemilikkan terhadap nilai pasar (Studi empiris pada Perusahaan Manufaktur yang Terdaftar di Bursa Efek Indonesia Tahun 20112013. Journal of Accounting. Vol 4. No 1. 1-12 pp.

Jong, D., Abe, M., Gerard, van der P., Marieke, \& Van Dijk, R. 2014. How Does Earning Management Influence Investors Perceptions of Firm Value. Survey Evidence From Financial Analysist. Review of Accounting Studies. Vol 19. No 2. 606-627 pp. 
Kim, D. ., Kim, B. ., \& Youn, M. 2017. Family Ownership and Firm Value: Perspective To Related-Party Transaction And Wealth Tranfer. Journal of Distribution Science. Vol 15. No 4. 5-13 pp. https://doi.org/10.15722/jds.15.4.20170 4.5

Li, J., Wang, B., \& Guo, H. 2017. Private Equity Characteristic Earning Management \& Firm Value. International Review of Accounting, Banking \& Finance. Vol 9. No 1.

Nurhayati, M. 2013. Profitabiltas, Likuiditas dan Ukuran Perusahaan Pengaruhnya Terhadap Kebijakan Deviden dan Nilai Perusahaan Sektor Non Jasa. Jurnal Keuangan \& Bisnis Program Studi Magister Manajemen Sekolah Tinggi IImu Ekonomi Harapan. Vol 5. No 2. 144-153 pp.

Sari, R. A. I., \& Priyadi, M. P. 2016. Pengaruh Leverage, Profitabilitas, Size dan Growth Opportunity terhadap Nilai Perusahaan. Journal IImu Dan Riset Manajemen. Vol 5.

Subanidja, S., Rahman, A., \& Astuti, A. D. 2016. Pengaruh Kepemilikkan Keluarga terhadap Kinerja Perusahaan dengan Agency Cost sebagai variabel Moderating. Jurnal Dinamika Akuntansi Vol 7. No 2.
Suffian, M. T., Mohd, M. S., \& Mastuki, N. 2015. Real Earning Management And Firm Value: Empirical Evidence from Malaysia. Malaysian Accounting Review. Vol 14. No 1. 26-47 pp.

Suprianto, E., \& Setiawan, D. 2018. Impact Of Family Control on The Relationship Between Earning Management and Future Performance In Indonesia. Business and Economic Horizons. Vol 14. No 2. 342-354 pp. https://doi.org/10.15208/beh.2018.25

Tandry, A. Y., Setiawati, L., \& Setiawan, E. 2014. The Effect Of CSR Disclousure to Firm Value With Earning Management As Moderating Variable: Case Study Of Non-Financing Firms Listed At Indonesia Stock Exchange. International Journal of Trade and Global Markets. Vol 7. No 3. 190-204 pp.

Yorke, S. M., Amidu, M., \& AgyeminBoateng, C. 2016. The Effects of Earning Management And Corporate Tax Avoidance on Firm Value. International Journal of Management Practices. Vol 9. No 2. 112-131 pp. 
2 Jurnal Pamator 